\section{Antropología y colonialismo: Anotaciones para el caso español *}

\author{
FERMIN DEL PINO DIAZ
}

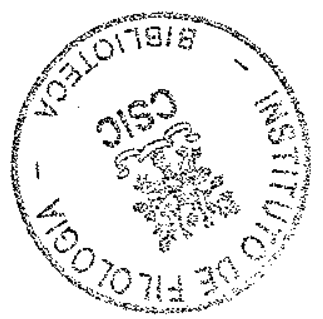

mo, que, aparentemente dio lugar a su creación y actual conservación. Posiblemente logremos con ello iluminar el papel futuro de este Museo, y de la antropología española, de acuerdo a su pasado, aunque este esfuerzo de $\mathrm{mi}$ parte no estoy seguro que pase a ser una primera tentativa. Tanto mejor cuanto antes sea superada, desde ahora lo declaro.

La primera cuestión que uno se plantea cuando quiere aplicar a España el tema Antropología y Colonialismo, en una época en que este país duda en si es colonizador o colonizado, es si hubo al menos en el pasado re. moto colonias, y sobre todo, si hubo antropología. La verdad es que, habida cuenta de la débil representación institucional que esta ciencia tiene en la Universidad, en los planes de enseñan$z a$, en el C. S. I. C. o incluso en la variada gama de Museos, y en lo reciente de su popularidad editorial, uno estaría tentado a dudar de su profundidad histórica. $Y$ en cuanto al colonialismo, la visión tradicional nos llega a hacer confuso el problema; unos por afirmar que aquello no eran colonias sino "provincias de Ultramar", y otros por describírnoslas más en términos de feudo de la tiranía y la barbarie que como paises monopolizados en su función de proporcionar las materias primas. Parece que hoy día comienza a haber un cierto acuerdo en la historia moderna para llamar propiamente colonias a los paises hispanoamericanos, asiáticos y africanos, de que hay muestra etnográfica en 
este Museo. Otra corriente parece afirmarse en aceptar la existencia de un cierto tipo de antropologia avant la lettre en la Espana del Renacimiento; después de la autorizada voz de algunos historiadores de America, espanoles o extranjeros -Alfonso Toro, Edward Bouncin. ton, H. Bancre, A. B. Bribs, J. D'Olwer, L Portilla P. de Tudela, EsDeve Ballesteros, J. A. Ma ravall, etco, seguida de cerca por la ravall, etc. segulda de cerca por la Espada o Alvarez López hay un enorme cúmulo de antropólogos, arqueóme cá yulo de antropologos, arqueoadmitido más o menos ampliamente admitido más o menos ampliamente Mitra, P. A. Means, A. Tozzer, A. Anderson, N. McQuown, J. H. Steward, M. Mead, J. Murra, M. Hodgen, J. H. Rowe, Joaquín Costa, L. Hoyos Sainz, A. Palerm, C. Lisón, etc.

No vamos ahora a tratar nosotros de este ya casi manido tema, pero quizá sea interesante reflejar aquí la opinión de uno de los mejores conocedores del mundo incaico y de los más dignos representantes de la nueRowe, para darlo por zanjado:

«La antropología no llegó a ser una tad del siglo $X X$ X hasta la primera miproblemas, ideas y actividades caracterís ticas son bastante más viejas. En un comunicación presentada ante la Sexta logical Society, en 1963, argumentaba yo que los comienzos de la antrapología han de ser vistos en el movimiento re nacentista de la Italia del siglo $\mathrm{XV}$, y especialmente en la arqueologia renacentista $y$ actividades paralelas. Lo que en contramos en el siglo XV, sin embargo,

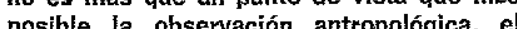
comienzo de un interés por las diferencias entre los hombres. En el XVI hubo una considerable expansión de la observación antropológica, y aqui nos encontramos ya con los primeros intentos do clasificar e interpretar los datos antro. pológicos... 'Tene interés el hecho de que siglo XVI... Las de 'etnografía' y 'etno- logia' no fueron acuñadas antes de finales del XVII.... El equivalente más cercano a en 1590 por José de Acosta como un pa ralelo a 'historia natural'... Una proporción sorprendentemente alta de datos etnográ́ítcos publicados en el siglo XV se refiere al Nuevo Mundo... El caso es que muchos de los mejores relatos de Bernardino de Sahagún, Diego de Landa y Cristóbal de Molina quedaron manuscritas hasta tiempos modernos... habiendo en España censura tanto eclesiástica co mo civil... El Gobierno español parece haber sido el primero en el siglo XV que logía aplicada... Hubo algunos libros de siglo XVI que intentaban ser estudios generales comparativos de aspectos particulares de la cultura... (Johann Boem, traducido por Francisco de Tamara en 1556, Jean Bodin). Para la mayoría de los escrtores del siglo $x$ V los terminos bárbaro, civilizado) constítuían una base para una deslavazada clasificación des criptiva sin implicación alguna de secuen cia o desarrollo... El redescubrimiento de la teoría clásica en el Renacimiento, de que los primeros hombres iban desnudos y habitaban la selva proveyó una base greso. Este desarrollo tuvo Iugar en el sigio XVI, cerca de cien años antes de lo que Bury sugiriese en su bien conocida obra sobre el tema (The idea of progress, Nueva York, 1952) 3. Pero tomó su asiento en la tradición de la filosofía social, no en el de la teoría etnovariedades humanas fue llevada a la tradiciốn etnológica por el desarrollo de un teoría de la evolución cultural. La figura clave en su desarrollo fue el sabio lesuíta del sigio XVI José de Acosta que... propuso clasificar todos los bárbaros en tres categorias: primero, los que han y por ello poseín un alto grado de civilización, como los chinos y japoneses, segundo, los que carecian de escritura, pero no de un gobierno organizado, una religión $y$ vivian en asentamientos estables, como los mejicanos y peruanos, vajes,

El profesor J. A. Maravall ha insistido en términos parecidos, y también sobre la intertermación de E. Panofsky, como Rowe, en su
pambién conocida obra de 1966 . Antiguos y también conocida obra de 1966, Antiguos
Modernos. La idea de progreso en el desarro-
Dentro de esta tercera hizo una distinción entre los que vivian como bestias ción y los més superiores que poseían los rudimentos de organización y erân más inclinados a la paz... Acosta argüía que los ancestros de los indios americanos fueron probablemente. salvajes, y que la Tum arrollo local desde origer era un desAcossa fue el primero, a lo que parece, de los escritores que intentaron formular un cuerpo de teoria etnologica distinto de la tradición de la filosofia social... EI esquema de Acosta es tan similar en los principios y en algunos de sus detalles wis $\mathrm{H}$. Morgan que de 1877 debido a Leque hayan pasado tres centurias entre

Una vez admitida esta calificación de "antropología" para la producción literaria de las crónicas españolas sobre América, podemos tranquilamente utilizar el caso español, entre otros, para incidir en la discusión que está teniendo lugar a nivel mundial como un fenomeno aparente de los anos sesenta. Probablemente la obra más conocida entre nosotros sea la tesis doctoral de Gerard Leclerc, escritítulo Españ su posible repercusión en de ella. Una obra así tiene una ubica. ción muy precisa dentro de la moderna antropología francesa de tipo tico, opuesta de algûn modo al quizá excesivo peso de tambien a una aparente exiguidad de presencia francesa en el pasedo con predominio aplastante anglosajón.

No hay que pensar que tal discusión ha estado ausente en este mundo anglosalon, ya que precisamente en nos alude a una discusión surgida en

${ }^{2}$ J. H. Rowe: Ethnography and Ethnology
in the Sixteenth Century, 1964 Berkeley, pas. in the Sixteenth Century,
sim, (traducción mía).

3 Anthropologie et colonialisme. Essal sur Anthropologie critique, 1972. Ha sido traduci$\mathrm{da}$, con deficiencias, aunque con un prólogo
inteligente por Comunicación, Serie B, Madrid,
Inglaterra entre antropólogos e historiadores, a propósito de la mútua dice:

«Por otra parte, otros, dentro de la disciplina (por ejemplo, Worsley, 1965: 1963), nos dicen, más o menos explícitamente, que la antropologia es un epifenomeno del colonialismo, tan vieja como él, y destinada a la extinción en las nue. liberación de Africa y Asientes a la cide, desgraciadamente, con la opinión sostenida hasta hace poco por algunos nacionalistâs africanos, pero que actualmente - por lo menos en aparienciaha perdido popularidad; que los antropó logos son tribalistas y, por lo tanto, opues.
tos al nacionalismo y a la modernidady].

Evidentemente el antropólogo Lewis no está de acuerdo ni en ello, ni en que la antropología deba reasumirse en la historia o la sociología. La integración nacional de los subgrupos del Tercer Mundo, y el proceso descolonizador no ha significado que degico, sino que en ello han tropolo. gico, sino que en ello han entrado pios antropólogos metropolitanos han comenzado a estudiar sus propios países al modo antropológico, todavía peculiar. Como veremos a continuación, Leclerc se deja llevar del "modelo explicativo" de los líderes políticos africanos que, inteligentemente, veían en la antropología decimonónica un argumento instrumental de la política imperialista; pero el lo intenta extender a la antropología como tal, y por eso concluye que el futuro de esta ciencia será integrarse en otras más "nobles" - historla, economia, sociologra- o volver a los "viajes filosóticoss del siglo XVIII francés, cual

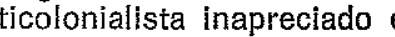
insubstituible.

En realidad, la alternativa historia o antropología, y sociologia o antropología es bastante más vieja, no sólo propio español: para los cronistas Historia y Antropologia. Ed. Seix Barral,
Sociedad Anónima, Barcelona, 1972, del origiSociedad Anónima, Barcelona, 
españoles del Renacimiento, "historia moral " es equivalente de "etnologia como hemos visto. Esta alternativa está resuelta en términos de colabora ción, y no de rivalidad, como hace Leclerc, desde hace bastante. Lecler confunde el problema: se trata de "historia de la antropologia" y de, incluso, "sociología de la antropología", y no de una u otra. Precisamente la vuelta al pasado que se está produciendo en la antropología (revalorización del evolucionismo por el nuevo tipo, llamado "multilineal"; la nueva actitud ante la historia, ya practicada en Tylor, Morgan, etc.; la inspiración en fuentes escritas, incluso literarias la nueva apreciación ideológica de los mitos como cosmologia, etc.), lo que trata es de encontrar las proplas tramanes academicas sin necesidad de man de una lucha cerdada sa de sus peculiaríades: por Boes. Malinowski y Radcliffe-Brown, de quie nes datan por otra parte harto ingrata para mantener en España donde el status re ción estrenado de esta ciencia le obligaría a una defensa desigual con sus hermanas mayores, al menos ahor y aquí, las ciencias sociales.

De lo que se trata es de hacer historia de la ciencia, y hasta hacer historia de la ciencia, y hasta sociologí de la ciencia. En este sentido si que la descolonización. Pero una discusión que será pertinente igualmente para otras ciencias sociales, como la economía, la historia, la lingüística o el derecho. ¿No es verdad que todas ellas han florecido en períodos coloniales? ¿Es que acaso toda ciencia no ha cumplido una función de poder, cargo de una administración expans: va? ¿Ello nos permitiría decir, por ejemplo, que cuando desaparecio monarquia habria de desaparecer la ciencia historica, por el hecho de haber narrado con más frecuencla las vidas de reyes que las de sus subditos? ¿Por el hecho de que la historia usa teorías económicas, enfoques sociologicos y criterios linguísticos o antropológicos, ya no es historia? prendente es que la antropología con- tinúe y sea aún más fecunda una vez que ha perdido lo que concederemos e recique es ciencia, al parecer, está recibiéses una progresiva aportación de Africa, como estudia Leclerc. Hay una creciente escuela en la India, en Japón, en México, en Argentina, en Australia y en Perú. Precisamente en México y en Perú se ha planteado recientemente el tema de la descolonización de la antropología, y parece como si ello hubiese favorecido su desarrollo, no al revés (Me refiero a la publicación del famoso escrito de cinco antropologos mexicanos De eso que llaman antropología mexicana, Barbado, 4970, y a la Declaración de Barbados, como consecuencia del Congreso Internacional de Americanistas tura lan, d famoso tanto ha preocupado al mentor de que tanto ha preocupado al mentor de Le$y$ en fecha poco anterior, es la siguiente declaración:

aDesgraciadamente hasta hoy, la antropología mexicana, que por muchos concepsos nos ha permitido conocer la realidad de nuestro país y que ha tenido un sentido humanista del problema indígena, ntica tuvo un sentido anticolonialista, ni pís. Influida por ciencia que precisamente surgió en los países metropolitanos para el estudio y control de los habitantes de sus colonias. no pudo proponerse como tema central cie estudio el problema del indígena como un problema colonial y como un problema
eminentemente politicon"s.

Quizá sea verdad lo que mantiene Leclerc de que:

«La situación colonial de la antropologia sólo ha aparecido con la desc
del tercer mundoy (1973: 14].

Pero acabamos de ver que países desconolizados hace tiempo, como México o Pera -descolonizados en el mismo sentido que los otros, ni más ni menos-, tampoco hayan sido cons-

${ }^{5}$ Pablo Goizález Casanova: La Democracia
en México, México, 1965, pá́gs. 88-9. cientes de ello hasta hace tan poco Seria dificil mant colonización Por otra observar que hayan parte, es curioso tiempo los antropólogos metropolita nos los que han criticado la implica ción "colonialistán y de dominio con que se han usado sus conocimientos. Malinowski a partir de 1930 Herskovits en 1944 y 1947, Marcel Griaule en 1949. La gama amplia de protestas en este sentido que incluye ya nombres como Levi-Strauss, E. R. Leach o Eric Wolf, puede extenderse hasta el mismo Las Casas, miembro vitalicio del Consejo de Indias bajo Felipe II: los tres primeros tambien han sido miembros de sociedades metropolitanas y son conocidos por sus teorías de "aculturación", de los que los do primeros son máximos exponentes.

Por el hecho de ser metropolitano de nacimiento, no queda implicado que se deba ser colonialista. Por el hecho de que los proplos conocimientos sean utilizados de manera diferente, no significa que se tenga responsabilidad: sería injusto hacer culpable a Marx de la política económica de los Estados Unidos, porque ésta se opera sobre bases en parte por él descubiertas: como también lo sería echar en el libro de cuentas de Las Casas la leyenda negra sobre España y los intereses imperialistas que encubría, de parte de Francia, Inglaterra y posteriormente de los Estados Unidos. En 1964, y como colofón de una seria investigación, el historiador-antropólogo norteamericano Charles Gibson de cía:

"La leyenda negra de una interpreta ción burda, pero esenclalmente justa do nas... su contenido esencial sostiene que los indios eran explotados por los españoles, $y$ de hecho lo fueronn.

Tres años más tarde, en un libro sintético y con una visión comparada del régimen colonial español, ya es tablece:

"La mayoría de las interpretaciones -indígenas han sida influenciadas por la Leyenda
Negra... Esta ha prosperado donde quiera que el anthispanismo ha llenado una parlantes y en la moderna Hispanoamerica. Su contra-argumento más común es que ella-aisló el caso español, concentrando su atención sobre la crueldad es. pañola, y olvidando la de otros pueblos... estrechamente concebida en tanto que castiga peculiarmente a España... En su mayor parte, sus defensores no han sido estudiantes de historia... Tanto la Le. yenda Negra como la Blanca se concen-

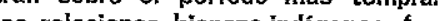

Cualquier antropólogo sabe que parte de la repulsa del Tercer Mundo hacia la antropología encubre también intereses "espúreos", y a la inversa que no todas las voces que acuden en su defensa abogan en la del aborigen: en ciertos países americanos pólogo porque "comunista" al antropologo porque estudia el problema de comunided con al oxterior; $y$ de una comunidad con el exterior; $y$ en otros conocin mantener sin plterar la situación para llanada sualistan. Según los casos tan colonialistan puede ser la postur, de conservar la cultura local como voluntad de alterarla: todo depende de a quién beneficie y sobre todo por quién sea decidido. Cuando un lider político africano o de cualquier país, decide atacar la antropología victoriana inglesa - como lo hiciera Omo Kenyata, Kwame Nkrumah, Jacques Rabemananjara o Sekú Turéhay que ver qué hace la antropología funcionalista, o la crítica de hoy. Pero su crítica homogénea se refiere a las implicaciones políticas y administra. tivas que ha tenido la antropología colonial, no a la antropología en general, como hace Leclerc, forzando los términos en una polémica más bien na-colonial. Ninguno de los intelectuales ni de los líderes políticos por él usados llegan a decir lo que él traduce

Los Aztecas bajo el dominio español
(1519-1810), 1964, trad. de F. C. E. de 1967, (1519-1810), 1964, trad. de F. C. E. de 1967, ginas 136-7 (traducción nuestra). 
de ellos: no es extraño que le parezca ambigua la postura del Tercer Mundo cuando rechazan la antropologia victoriana, al menos la practicada por la Administración inglesa y francesa en Africa $y, \sin$ embargo, reconozcan otros productos occidentales como ciencia, y con ella la antropologla. El mismo presidente de Kenya, Omo Kenyatta estudio en Londres y escribio un libro de antropologia: Al pie del monte Kenya (1937). Las facultades de antropologia de Inglaterra, Francia Estados Unidos están llenas de estudiantes del Tercer Mundo, general mente politizados; procuran no llegar a decir sobre su país las tonterías que Leclerc, sin suficiente espiritu crítico, recoge del senegalés Cheikh Anta Diop sobre la pretendida homogeneidad del patriarcado europeo sus funestas consecuencias en el Estado-cludad, el patriotismo, la xenocobia, el individ, la desgana por la moral y material, la desgana por existencia, y cosas por el estilo (Le-

Frente a estas afirmaciones, que i siquiera se le ocurrían a los evolucionistas victorianos, cualquier antropólogo de hoy subscribiría las palabras del malgache Jacques Rabemananjara:

"El negro se ha hecho bárbaro el día en que el blanco se ha dado cuenta de la ventaja de la barbarie. El desarrollo del capitalsmo en el siglo XIX y su expansión en ultramar tenian necesidad de una justificación: el mito ha nacido de una inquietud de elegancia moral, y la tabula de la nación mas nobles" (Leclerc, 1973: 196, dicho en 1956, dos años después de lo de Diop).

Por ello mismo, y para evitar las ambigüedades de la "colaboración". es por lo que la teoria evolucionista ha sufrido un abandono general en los años inmediatos a la Prmera Guerra Mundial, y por lo que la colaboración de los antropólogos en los planes Gubernamentales de Inglaterra y luego en Estados Unidos y Francia ha estado marcada de una tremenda hostlidad desde la terminación de la Segunda Guerra Mundial, y progresivamente se ha ido yendo hacia una reclusión en la teoría y en el academicismo, que parecia estar menos sujeto a la utillzación. Solamente tras la descolonización, está siendo posible volver hablar otra vez de una antropología aplicada, aunque más como derecho la protesta y defensa de los derechos ocales, que como técnica codificada de los conocimientos aplicada al desarrollo de la salud, el alfabetssmo y el desarrollo económico. Los temas recurrentes de la investigación antropológica de hoy, tanto en las antiguas metrópolis como en las antiguas colonias mas activas, versan masivamente sobre tenencia de tierra, organización social y política, movimientos de rebellón, y visión indígena ante los cambios.

Quizá a causa de esto sufran un poco injustamente una preterición ciertos temas caros a todo antropólogo, pertenecientes al campo ideológico y religioso. Muy significativamente, asoma la voz de uno de sus mejores the de Leclerc para revelar esta injusta vez que se le deja hablar, aunque sean muchas las que se le cite:

"Las poblaciones manifiestan una cre. ciente intolerancla hacia la investigación temen cus, bajo la capa de una visión etnográfica de los hechos humanos, tratemos de hacer pasar por diversidad de seable lo que les aparece como insoportable desigualdad... los antiguos pueblos colonizados no veían en ella un proble ma interno de la hlosolla occidental, sh no la expresión objetiva de una relación suyas Por una curiosa paradoja no cabo cuda de que muchos etnólogos habían adoptado la tesis de la diversidad, que parecía excluîr la hipótesis de socieda. des inferiores, por consideración hacia ellas $Y$ ahora estos mismos etnólogos son acusados de haber negado esta infe Iaria y asi mantenerta meiorn (Leclerc. larla y así mantenerla mejorn (Leclerc

Este mismo autor poco antes, había visto igualmente el desarrollo de la
Antropología aplicada en los Estados
Unidos, y para uso interno, como una prueba de crisis interna de la socielad metropolitana, adoptando una viión dialéctica de que le creen carente sus impugnadores:

"En los EE,UU. se asiste desde hace diez años a una evolución sensacional que es, sin duda, reveladora de la crisis espiritual que experimenta la sociedad noteama a dudar do si misma y no logra ya aprehenderse, si no es por medio de esta incidencia de lo extraño que ella adquiere cada día más ante sus propios ojos)..... ${ }^{7}$.

añu más tarde continuará afirmando para responder a este equívoco cada vez más extendido:

...lo que Ilamamos Renacimiento fue, tanto para el colonialismo como para la

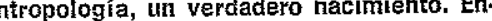
tre uno y otra, enfrentados a partir do

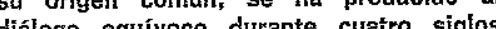
ext I surgimiento de la antropología hubiera sido menos tardí; pero tal vez la antropología no se habría visto llevada a desempeñar el papel que ahora es el suyo - cuestionar al hombre mismo en cada uno de sus ejemplos particulares. Nuestra ciencia alcanzó la madurez el dí en que el ho are occidea comí comprendese a si mismo, mientras so bre la superficie de la tierra una sola raza o un solo pueblo fuera tratado por él como un objeto. Solamente entonces la antropologia ha podido afirmarse como to que realmente es, un esfuerzo, que renueva y espia el Renacimiento por exHumanidad ${ }^{8}$.

De esta visión dialéctica, a nivel interno de la metrópoli y a nivel in terno de las colonias, carece Leclerc, y es sintomático que el mismo prologuista de la tradúción españoles se lo tenga que echar en cara:

«...Algunas afirmaciones de Leclerc son lo suficientemente polémicas como para que resule exte polkmicas como para

7 C. Lévi-Strauss: Antropología Estructural, cadas - por ejemplo, la cuestión de sl las uchas independistas en los paises tercer mundo han sido prinordlalmente (1973:10).

Porque, y quizá creyendo demasiado en las tesis de algunos dirigentes de Tercer Mundo, ya que la obsesión suya es la de no "reducir" el pensamiento indigena al occidental como cree que hacen los antropólogos, Leclerc todavía cree que la integración entre la metropoli tradicional y su colonia, ha sido rota por los movimientos de independencla, ya que en realidad se trata para él de una lucha nacionalista. Peque esto sólo se le ha ocurrido a los inte líderes del Tercer Mundo y a lo que parece a los africano de los años cincuenta. Para nosotros, por el contrario, esta tesis coindice, quizá umilagrosamente con las de las nuevas metrópolis. Por otra parte, no son tesis de hoy, sino que parte, no son tesis de hoy, sino que pueden encontrarse predominando en las defendidas por el Virrey Toledo respecto a los pueblos sometidos al poderío, o "tiranía" para ser más exactos, de los incas. Son las defendidas en la Francia de la Revolución francesa, recién acabada la Independencia de los Estados Unidos, en la que tanto participase ella. Son las argüidas en Inglaterra, cuando la independencia de América del Sur, o en Estados Unidos, cuando la de América antillana y Filipinas. $Y$ han pasado por ser tipicamente "occidentales" - de Francla, URSS diales. La forma política que han dedibo adoptar los puebios para ser "estados civilizados" ha sido la democrática, y muchos de estos dirigentes que tanto criticaban la antropologia victorlana son sus representantes. Evidentemente, la estabilidad politica no puede ser la norma de tales Estados, puesto que la opinión de sus concludadanos no colndice con la suya, listas".

Idénticamente no todos los ciudadanos de las metrópolis coinciden con 
las tesis de sus gobernantes, sino tienden algunos más bien a verse re presentados en ciertas corrientes de pensamiento del Tercer Mundo. Algunos de ellos, incluso, creen más inte resante la cosmología de algunas mi norías no "re-absorbidas" del Tercer Mundo por la corriente modernizadora que ha seguido a la descolonización, que la continuación de la filosofía llamada occidental, pero ya poco representativa de toda la variada gama que Occidente ha contenido, al menos hasta el Renacimiento, $y$ que ha inhasta el Renir defendiendo cada in tentado segúr de Y lo mismo que de con menos exilo. Yo mismo que de en la economía, la sociedad, la política, el arte y la religión de estas minorías del Tercer.Mundo: quizá $\mathrm{ml}$ la antropología la que está más convencida de la relación estrecha que existe entre todos estos temas. Desde luego, han sido los antropólogos, y especialmente desde el Renacimiento del siglo $\mathrm{XV}$, aunque tienen evidentemente sus precursores, y no sólo posiblemente en Occidente, los que más se han interesado en esa contradicción, que Leclerc llama ureducción". Otra vez, Levi-Strauss, profundo conocedor de la historia de la antropología, no sólo de la francesa, nos apoya en este trance:

"Sin duda, nos dice, el desarrollo del pensamiento moderno ha favorecido la crítica de las costumbres. Pero este fenómeno no constítuye una categoría extraña al estudio etnológico: es más bien
su resultado, si es verdad que su princisu resultado, si es verdad que su princi-
pal origen se encuentra en la formidable pal origen se encuentra en la formidable
toma de conciencia etnográfica que suscitó en el pensamiento occidental el des. cubrimiento del Nuevo Mundos".

Es una verdad demasiado general para que haya pasado desapercibida a otros. Paul Mercier, igualmente francés e igualmente conocedor desde afirma taxativamente:

Antropología Estructural, 1969, Buenos
¿La antropología, y más generalmente las ciencias sociales, nació de una crí trecuencia de un modo indirecto median te la utopía, y de una toma de conciencia del relativismo de las culturas. Estos temas han permanecido subyacentes en su historia. No existe utopia, ni teoría politica que no tenga en cuenta a partir de naturaleza' que, según unos, precede las corrupciones de la civilización, o que por ef contrario permite comprender los fundamentos de la misman so.

De la misma manera ha sido vista por el historiador español del pensa miento político hispano, J. A. Maravall:

"La aceptación jurídica y moral de los oúros, de los discrepantes, sin que poda. fuerza en apoyo de la ortodoxia -Vitoria declara expresamente su sospecha acerca de Ia ilegitimidad de los medios que en América se han empleado- queda bien de manifiesto en Vitoria desde su misma aíz. Y si en el $-y$ ello ya era mucholas bases estarán dadas para considera ciones semejantes a los discrepantes dentro de un mismo grupo, cuando el conocimiento psicológico y moral del mundo interior de la convivencia haya sido pro-

El profesor llamará a Vitoria y a otros neoescolásticos "teólogos de la época mercantiln, aprovechando el precedente de haberse llamado a Descartes sfilósofo de la época de la manufactura"s porque su ciencia, o lo que sea, la ha derivado del cosmopolitismo adquirido en el trato con los mercaderes, y en el aprendizaje sobre la pluralidad de Estados renacentistas. Esto es lo que se llamaria una que él supera en algún momiento", que el supón de to que dice muy en su favor. Como el prólo muy en su favor. Como en lémico con que nos ha regalado ultimamente: 10 Historia de la Antropologia, 1968, Barce-
lona, págs. 32 .

"La oposición politica en la época de lo
«No se trata de descubrir grandes creadores de teorias, que no en todas
partes existen, pero sí de ver cómo la penetración, asimilación crítica, reelaboración, efc., de ideas sobre la política,
la economía, el derecho, la historia, el la economia, el derecho, la historia, el arte, la ciencia, la religión o, en una sola relación dialéctica con el estudio de la sociedad españolàs ${ }^{12}$.

Del profesor Maravall esperamos muchas cosas, y entre ellas una "historia del exotismo españoln, que nos tiene prometida por escrito; pero esperamos mucho igualmente del profesor J. L. Abellán, del profesor Roberto Mesa y de otros historiadores de España y America, que comienzan a interesarse por esta joven ciencia española de la Antropologia. Quizá nos ayuden a descubrir sus profundidades históricas al Renacimiento, y quizá nos ayuden a entender las condiciones historicas con que nuestra ciencia progresa o se detiene. Afortunadamente, con ellos la relación no se promete rival, ni nos obligan a crear una historia defensiva y rosa de nuestra antropologia, que de nada serviría ni a las otras antropologias, $\mathrm{ni}$ al Tercer Mundo, $\mathrm{ni}$ a nosotros mismos, puesto que nada aprenderiamos. Si que tenemos mucho que aprender de la manera magistral con que los médicos están construyendo la historia de su ciencia, bajo la dinrección de Lain Entralgo, Lopez más, cuanchez Grangel y muchos Ia antropología intentaremos corresla antr. Ouiź nos ayude a ello la pobra ya voluminosa, de nuestro maestro Caro Baroja cuyas indagaciones en la historia de nuestros pent sobre la magia y sus condiciones his tóricas peculiares, ya son clásicas. toricas pecullares, ya son clasicas. al apelativo de "Antropólogo" con toda la carca de defensa personal que el nombre ha llevado consigo en Oc cidente, y en este país en especial: quizá en ello sea más antropólogo de espíritu que muchos de nosotros.

Yo quisiera, a continuación, ofrecer unas pinceladas de lo que debía ser

${ }_{12}$ Op. cit., pág. 9
Ia historia de la antropología españo la, en contraste con el ejemplo del señor Leclerc, y a propósito de su relación con el colonialismo. Aprovechemos su lección de que lo único que puede permitir una visión autorizada sobre las líneas futuras de una ciencia, es el conocimiento de su pasado; pasado que sólo se explica relacionando la ciencia con la sociedad en que se hizo, con la dinámica de sus intereses y la contradlcción de sus personajes, que intentaran retiejar en sus ldeas y sus metodos. Tambien tomamos nota del lastre patriotico de todas las historias: podemos declarar, tras habernos leido unas cuantas Mercier Harris Mitra, Poirier, Levi-Strauss, Durkheim Van Gennep, Beals, Hoebel, Pocock, EvansPritchard, Prichard, etc.- que la gran mayoria apoyar las convicciones teóricas del apor Sólo recientemente se comienzan a plantear sinceramente las comparaciones de estas historias nacionales de modo más crítico: ahí están los ejemplos de Lienhardt, Hodgen. Eggan, Rowe, Hallowell o Palerm. Se da la coincidencia de que, conforme se amplía el horizonte temporal a historiar, van desapareciendo las prioridades de unos héroes sobre otros - según la tendencia del autor- y van surgiendo los paralelos sorprendentes, aquellos que nos sugieren alguna explicación sobre el derrotero de la propia ciencia por encima de los propios gustos.

Si el señor Leclerc se hubiera tomado en serio los precedentes clásibiera ofrecido el cuadro parcial que resulte no sólo del siglo XVIII francés, sino del XIX inglés y del XX norteamericano, francés e inglés. ¿Cómo americano, francés e hoy aludir al umodo asiático de producción" en Marx y no conocer la escuela norteamericana del evolucionismo multilineal, a la que ni siquiera nos alude? ¿Cómo se puede aludir al evolucionismo victoriano olvidarse de los franceses Boucher de Perthes y Fustel de Coulanges, de los racistas Comte de Gobinau y 
Vacher de Lapouge, sus probables iniciaciones bajo la forma «segregadora en que hoy se la conoce? ¿Cómo hablar del funcionalismo sin darnos a veces ni referencias de la obra de Franz Boas, la de Radcliffe-Brown Franz Bous la de Radclife-Brown la de Durkhelm on una nota? ¿có apenas se les cita en una nota? ¿Cón mo se puede aceptar su afirmación de que el siglo XVIII no era etnocéntrico ni conocia el colonialismo, sabiendo que crearon el concepto de "progreso" y poseían a sus puertas la esclavitud?

Muchos de estos defectos son propiamente whuecosn, lagunas en su conocimiento que podrian resolverse con la lectura de Manuales de Antrocon la lectura de Modric pologia: all, por ejemplo, nos dicen que el significado de esquma no es hombre, sino crudan (1973; 171: sin error de traducción) y nos aclaran a cuáles podemos considerar "maestros de las escuelas etnologicas", y cuales son las tendencias principales. Otros errores de omision ni siquilera pueden resolverse en tales Manuales e Historias profesionales: ahí es donde necesitamos la colaboración de los historiadores, y en especial de los historiadores de las ideas. De ellos en España estamos verdaderamente necesitados, $y$ dependemos grandemente de sus se ha dedicado a la antropología, fuera de ciertos prólogos.

Nosotros propondríamos a nuestros colegas que hicieran parte de esas historias, conforme se fueran topando con manuscritos, con memorlales o con publicaciones inaccesibles. Personajes como Joaquin Costa, Rafael María de Labra, Ramón de la Sagra, Machado y Alvarez o el mismo ValleInclán han servido de fuentes, y sería desperdiciar la ocasión no incluir un examen de su mentalidad, desde un punto de vista antropologico. Como diria nuestro historlador Americo Castro, del que tantos elementos hemos podido aprovechar para la in Xagación en la mente y vida del siglo XVI, que cha averiguación de lo que es con propósito cientifico, una vez realizado, presmuchos o pocos quienes la entiendan. En el pensamiento teórico de nuestro tiempo hay muchas verdades que de veras existen y funcionan en un número muy limitado de cerebros... No se trata, por lo tanto, de fijar univocamente el ser de to que es, sino de hacer ver cómo existen personas. Esta forma de historia o de averiguación humana, es de suyo indiscre. ta $\mathrm{y}$ desagradable para quienes no temen una actitud anuente frente a ella. Será en cámbio, válida para quien acepte no sólo su verdad, como en el caso de una realidad abstracta, sino para guen se vida haia panoramas distintos de ellos para êl habituales. Las grandezas o desdichas del pasado o dquiririán entonces otro sentido, cabrá en lo posible idear nuevos modos hispanicos de estar el pueblo es. pañol apegado a la imagen de su propia vida, una imagen a la vez suya y falsan'

Por nuestra parte, estamos orientando nuestra investigación del siglo XVI español, de manera que pueda aplicarse posteriormente a otros siglos, por nosotros o por los demás, y para la ciencia española, o para la extranjera. Estamos intentando hacer una historla sociologica de la antropología del Descubrimiento de no rica, sigulendo un camino que no es de todo nía y había otros modelos nortopric manera:

Conviene hoy hacer al fin la historia detallada del pensamiento etnológico, $\mathrm{y}$ a a sociologia de la enología significa intentar, para cada período, destacar las

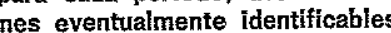
entre la evolución del conocimiento del hombre, por una parte, y las creencias religiosas, Ia situación polftíca, el medio tecno-económico, la etica $y$ el sistem historì del enfogue del hombre por el hombres 14 .

Español, palabra extranjera: motivos y
azones, t970, Madrid, págs. $93-4$. razones, 1970, Madrid, págs. 93-4. 14 Histoire de l'Ethnologie, 1969. Paris, pá
gina 125.
Nosotros, efectivamente, hemos encontrado ciertos paralelos entre la EsPViI del siglo XVI, la Francla del américa del XX de XIX y la NorteXV , a cuyo estudio nos animaba Rowe como un precedente directo del español y del francés e inglés. Eran sociedades en expansión, en plena época de subrimientos, con nuevas realidades humanes como un reto para ser comprendidas: eran sociedades con una pujanza industrial o artesa nal, y con un proceso de abandono de los campos, y hacinamiento en las ciudades, que puede explicarnos algo de la presencia común de una pica resca, una literatura sobre la pobreza y una utopía; eran sociedades que se asomaban al pasado -en la Biblia o en Ios clásicos- con una ansia verda deramente incontenible de "explicaciones» y de modelos anteriores de explicación, quizá al fin con una "perspectiva historican. Nos ha sorprendido el predominio de cronistas religiosos, más bien regulares que seculares, en una êpoca de reforma eclestástica y de pugna Iglesia-Estado nacional, todavla probablemente sin decidir hasta mediados del siglo XVI al menos en España. Nos ha sorprendido el predominio de personajes críticos, entre los cronistas de interés indígena, a algunos de los cuales se les ha colgado el sambenito de conversos - Las Casas, Bernardino de Sahagún, Oviedo, Acosta. Nos han admirado las alusiones a sus recuerdos de infancia y a su localidad, que en ellos, especialmente en Sahagún.

Quizá lo que el antropólogo ha ido a buscar a tierras lejanas, y lo que continua buscando en los campos y imperialista» o "nacionalista que otros le puedan dar, no sea sino la persistencia de esa comunidad local que él ya vivió en trance de extinción y sin la suficiente frescura que le muestran todavía sus actuales sujetos de estudio.

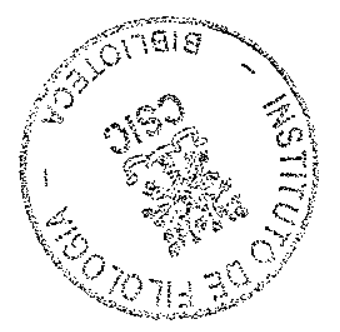

